\title{
Modelling and experimental investigation of effects of moisture and operating parameters during the adsorption of $\mathrm{CO}_{2}$ onto polyaspartamide
}

\author{
Kelvin O. Yoro ${ }^{1} \cdot$ Mutiu K. Amosa ${ }^{2,3} \cdot$ Patrick T. Sekoai $^{1} \cdot$ Michael O. Daramola $^{1}$ (D)
}

Received: 7 May 2018/Revised: 17 July 2018/Accepted: 4 September 2018/Published online: 17 September 2018

(C) The Author(s) 2018

\begin{abstract}
Parametric effect of moisture and influence of operating variables on the adsorption behaviour of polyaspartamide during $\mathrm{CO}_{2}$ capture was investigated in this study using experimental and modelling approach. Individual effects of operating conditions (e.g. pressure, temperature and gas flow rates) as well as the effect of moisture on the adsorption capacity of polyaspartamide were methodically investigated using Dubinin-Raduskevich model. Results from the investigations reveal that the presence of moisture in the flue gas had an incremental effect on the adsorption capacity of polyaspartamide; thereby showcasing the potential of polyaspartamide as a suitable hydrophilic material for $\mathrm{CO}_{2}$ capture in power plants. In addition, pressure, temperature and gas flow rates at $200 \mathrm{kPa}, 403 \mathrm{~K}$, and $1.5 \mathrm{~mL} / \mathrm{s}$, respectively, significantly influenced the $\mathrm{CO}_{2}$ adsorption capacity of polyaspartamide. Physisorption and chemisorption both governed the adsorption process while equilibrium studies at different temperatures showed that Langmuir isotherm could adequately describe the adsorption behaviour of the material with best fit with $R^{2}>0.95$.
\end{abstract}

Keywords Adsorption capacity $\cdot \mathrm{CO}_{2}$ capture $\cdot$ Moisture $\cdot$ Operating variables $\cdot$ Polyaspartamide

\section{Introduction}

Coal is one of the world's cheapest and abundant fossil fuel with a wide range of applications in power generation, transport systems and thermal energy production (Chitsiga et al. 2018). However, the use of coal in these important sectors results in the emission of greenhouse gases (especially $\mathrm{CO}_{2}$ ) into the atmosphere which is a major cause of climate change. Discontinuing the use of coal especially in

Michael O. Daramola

michael.daramola@wits.ac.za

1 School of Chemical and Metallurgical Engineering, Faculty of Engineering and the Built Environment, University of the Witwatersrand, Private Bag X3, Wits 2050, Johannesburg, South Africa

2 Environmental Engineering and Management Research Group, Ton Duc Thang University, Ho Chi Minh City, Vietnam

3 Faculty of Environment and Labour Safety, Ton Duc Thang University, Ho Chi Minh City, Vietnam power generation or switching to other alternative clean energy sources will make power generation very expensive and unaffordable in most developing countries (Sekoai et al. 2018; Yoro and Sekoai 2016). Research have shown that by applying $\mathrm{CO}_{2}$ capture and storage techniques, it is possible to continue the use of coal in power generation and yet maintain a near-zero $\mathrm{CO}_{2}$ emission. Adsorption of $\mathrm{CO}_{2}$ is a reliable technique that can be used for $\mathrm{CO}_{2}$ capture and adsorbents play a critical role during this process.

So far, variety of adsorbents such as synthetic zeolites (Cheung and Hedin 2014; Siriwardane et al. 2005), aminegrafted zeolite $13 \times$ (Bezerra et al. 2014), amine-grafted activated carbon (Alhassan et al. 2017; Hao et al. 2017; Zhang et al. 2013), amine-modified polymethyl methacrylate (Lee et al. 2008), carbon molecular sieves (DonaldCarruthers et al. 2012; Lee and Park 2015), silica and metal oxides (Chowdhury et al. 2015; Li et al. 2015; Zhang et al. 2014b), as well as metal organic frameworks and aminemodified materials (Belmabkhout et al. 2016; Fracaroli et al. 2014; Zhang et al. 2014b) have been developed and 
studied for $\mathrm{CO}_{2}$ capture under both dry and wet conditions. Before now, amine-grafted zeolite $13 \times$ and carbon molecular sieves were used for $\mathrm{CO}_{2}$ capture because of their high $\mathrm{CO}_{2}$ adsorption capacities at low $\mathrm{CO}_{2}$ concentration $(258 \mathrm{mg} / \mathrm{g}$ for amine-grafted zeolite $13 \times$ and $950 \mathrm{mg} / \mathrm{g}$ for carbon molecular sieves), rapid mass transfer in the particle, and other factors such as cheap preparation cost and environmental friendliness ( $\mathrm{Li}$ et al. 2013; Samanta et al. 2012; $\mathrm{Xu}$ et al. 2002, 2005). However, $\mathrm{CO}_{2}$ adsorption capacity of these adsorbents tend to decline rapidly in the presence of moisture with a slight increase in temperature (Xu et al. 2011). In response to these challenges, polyaspartamide was recently developed for $\mathrm{CO}_{2}$ capture but the effects of operating conditions on its behaviour during the adsorption of $\mathrm{CO}_{2}$ has not been adequately reported in open literature. Hence, it is investigated in this study.

Polyaspartamide is an amine-grafted polysuccinimide. It is non-toxic, biodegradable and environmentally friendly with a high degree of porosity and extended inter-particle surface area widely used in chemotherapeutic studies (Kim et al. 2012; Miyata et al. 2008; Moon et al. 2011). Its rich amine-content, high thermal stability, high adsorption capacity and ability to be regenerated after use makes it a potential material for $\mathrm{CO}_{2}$ capture. Details on its preparation and cost have been reported extensively in our previous works (Ngoy et al. 2017; Chitsiga et al. 2016). Hence, it is not repeated in this work. As far as could be ascertained, no information has been provided in literature in contrast with impregnation or grafting of polyaspartamide because the material is still new in the area of $\mathrm{CO}_{2}$ capture. Grafting and impregnation of polyaspartamide with other materials could be considered by future research. Since the application of polyaspartamide in $\mathrm{CO}_{2}$ capture is still new; a detailed report on its behaviour during the adsorption of $\mathrm{CO}_{2}$ is crucial towards attaining efficient separation. It has been identified that there is a dearth report on the behaviour of the adsorbent in the presence of moisture (Scapino et al. 2017). In-depth information on the influence of operating conditions on the adsorption capacity of adsorbents as well as the optimization of these operating conditions during $\mathrm{CO}_{2}$ capture is also very pivotal in the design of adsorbents and adsorption systems to ensure a good $\mathrm{CO}_{2}$ adsorption capacity. Therefore, the main objective of this study is to provide useful parametric information that could be used to optimize polyaspartamide as an adsorbent for effective $\mathrm{CO}_{2}$ capture in the presence of moisture. This is because, for adsorption of $\mathrm{CO}_{2}$ to be economically feasible during post-combustion $\mathrm{CO}_{2}$ capture, there is a need for the development of adsorbents with high adsorption capacity and very high moisture resistance (Cuéllar-Franca and Azapagic 2015; Scapino et al. 2017).
A typical industrial flue gas contains moisture and the adsorption capacity of most adsorbents is chiefly determined by the conditions at which they are put into use. The composition of flue gas from a typical power plant is usually $68 \%-75 \% \mathrm{~N}_{2}, 10 \%-15 \% \mathrm{CO}_{2}, 5 \%-10 \%$ moisture and $2 \%-5 \% \mathrm{O}_{2}$ with traces of $\mathrm{NO}_{x}$ and $\mathrm{SO}_{x}$ (Ntiamoah et al. 2016). Conventionally, the wet flue gas from power plants is usually pre-treated and dried to reduce its moisture content before adsorption process commences (Ntiamoah et al. 2016; Xu et al. 2011). This conventional approach of pre-treating and drying flue gas before capturing the $\mathrm{CO}_{2}$ content is widely embraced industrially. However, this option increases the overall cost of the $\mathrm{CO}_{2}$ capture process and also impacts negatively on plant efficiency (Sekoai and Yoro 2016; Yoro 2017; Zhang et al. 2014a, b, c). In addition, most adsorbents adsorb moisture alongside other gases and this makes the $\mathrm{CO}_{2}$ separation selectivity to become very low during the capture process (Marx et al. 2013; Yoro and Sekoai 2016; Zhang et al. 2014a, b, c).

The key elements of a good adsorbent for $\mathrm{CO}_{2}$ capture are; rapid adsorption/desorption kinetics, moisture resistance, stable adsorption capacity after repeated cycles and adequate mechanical strength of the particles (Titinchi et al. 2014; Veneman et al. 2015; Yu et al. 2017). Most of these key elements for a good adsorbent have been studied and reported in literature for most adsorbents (Alhwaige et al. 2016; Ding et al. 2016; Osler et al. 2017a, b; Singo et al. 2017; Yoro et al. 2016; Ngoy et al. 2017; Sekoai et al. 2016). The effect of moisture on adsorbents during $\mathrm{CO}_{2}$ capture needs to be studied in-depth because most times, moisture usually occupy the pores of adsorbents and most adsorbents have exhibited a higher affinity for moisture than $\mathrm{CO}_{2}$ (Amponsah et al. 2014; Leung et al. 2014). The effect of moisture on the adsorption capacity of adsorbents during $\mathrm{CO}_{2}$ capture could be advantageous or detrimental (Marx et al. 2013). Hence, if polyaspartamide must be considered as an appropriate material for $\mathrm{CO}_{2}$ capture from power plants, there is need to understand the effect of moisture on its adsorption performance during the $\mathrm{CO}_{2}$ capture process (Marx et al. 2013; Qi et al. 2000).

Previous studies have speculated that amine-rich polymer-based adsorbents exhibit a high tolerance level for moisture (Chou and Chiou 1997; Hefti et al. 2014). Similarly, the effect of vapour pressure on the adsorption capacity of other $\mathrm{CO}_{2}$ capture materials have been described using the popular Langmuir, Freundlich, and DubininRaduskevich models in the past (Chou and Chiou 1997; Guangzhi et al. 2017; Vargas et al. 2012); as such, a similar approach was adapted and modified in the investigation reported herein to confirm the aforementioned speculation.

Synthesis and characterization of polyaspartamide have been adequately reported in our previous works (Chitsiga et al. 2016; Ngoy et al. 2017; Yoro et al. 2017). A study on 
the kinetic behaviour of polyaspartamide has also been reported recently (Yoro et al. 2017), but the influence of moisture and other operating parameters on the adsorption capacity of polyaspartamide during the adsorption of $\mathrm{CO}_{2}$ from a flue gas stream is rare and has not attracted adequate attention in the past. Therefore, the current study is focused on the investigating the influence of key operating variables during adsorption of $\mathrm{CO}_{2}$ by polyaspartamide and the effect of moisture on its adsorption capacity during $\mathrm{CO}_{2}$ capture. The modelling and experimentation approach adapted in this study is simpler, straightforward and better suited than the original graphical technique commonly used for dynamic simulation of activated carbon adsorbers and it have been confirmed to be suitable for parametric studies of this kind from related studies (Alhassan et al. 2017; Chou and Chiou 1997; Yoro et al. 2017). The outcome of this study is expected to provide useful information that could be used to optimize polyaspartamide as an adsorbent for effective $\mathrm{CO}_{2}$ capture.

\section{Materials and methods}

\subsection{Materials}

The materials used in this study include; polyaspartamide, gas mixture (Composition: $15 \% \mathrm{CO}_{2}, 85 \% \mathrm{~N}_{2}$ ), and pure Nitrogen gas $\left(100 \% \mathrm{~N}_{2}\right)$. Polyaspartamide used in this study was not procured but synthesized in our laboratory according to a modified protocol described by Ngoy et al. $(2014,2017)$ while all gases used in this study were purchased from Afrox (Pty) South Africa and used without any further purification. The gas analyzer considered in this study is a single component $\mathrm{CO}_{2}$ gas analyzer (Model: ABB-AO2020, Dimension: $485 \mathrm{~mm} \times 460 \mathrm{~mm} \times 135$ $\mathrm{mm}$, Weight: $15 \mathrm{~kg}$, Precision: $\mathrm{SO}_{2}, \mathrm{NO}, \mathrm{CO}, \mathrm{CO}_{2}$ $\leq \pm 2 \%, \mathrm{O}_{2} \leq \pm 3 \%$, Place of manufacture: Frankfurt, Germany). The analyzer was used to obtain the concentration of $\mathrm{CO}_{2}$ adsorbed by the adsorbent.

\subsection{Methods}

The sample (polyaspartamide) was pre-treated by heating at $353-373 \mathrm{~K}$ under vacuum $(0.01-0.05 \mathrm{kPa})$ for $1 \mathrm{~h}$ to desorb $\mathrm{CO}_{2}$, water and other gaseous impurities that could be present on the sample. The adsorption column temperature was then cooled down to room temperature (298 K) and re-pressurized with $\mathrm{N}_{2}$ gas. Afterwards, the temperature was adjusted to the desired adsorption temperatures. Experimental data obtained from the adsorption experiments were fitted into mathematical models adapted from a similar study (Chou and Chiou 1997), and then analysed in order to describe the effect of moisture on the adsorption capacity of polyaspartamide while the influence of operating conditions on the adsorption capacity of polyaspartamide was studied experimentally at different operating conditions in a packed-bed adsorption system. Within the experimental conditions in this study, the adsorption capacities of polyaspartamide in both moist and dry air streams were related to the operating pressure, gas flow rate and adsorption temperature.

\section{Experimental procedure}

Experimental runs were first carried out to determine the adsorption capacity of polyaspartamide in a laboratoryscale packed-bed adsorption column at operating temperatures of 403,418 and $433 \mathrm{~K}$, as well as a pressure range of 100-200 kPa. Polyaspartamide $(0.1 \mathrm{~g})$ was loaded into a column and pure $\mathrm{N}_{2}$ was used to purge the adsorption system at $373 \mathrm{~K}$ at an inlet gas flow rate of $1.5 \mathrm{~mL} / \mathrm{s}$ for $10 \mathrm{~min}(600 \mathrm{~s})$ to get rid of impurities within the column. To proceed with the main experimental runs, the initial temperature was lowered to $433 \mathrm{~K}$ and the concentrations of $\mathrm{CO}_{2}$ were obtained from the digital $\mathrm{CO}_{2}$ gas analyzer at different times. The feed gas $\left(15 \% \mathrm{CO}_{2}, 85 \% \mathrm{~N}_{2}\right)$ was then fed into the adsorption column while by-passing the reactor in order to obtain the initial concentrations of $\mathrm{CO}_{2}$ at different temperatures. More experimental runs were repeated at 418 and $403 \mathrm{~K}$, respectively. Each experimental run lasted for $1200 \mathrm{~s}$ at different operating conditions. At any given temperature considered, the quantity of gas adsorbed was a function of the pressure. Adsorption capacity of the material was then mathematically calculated from the mass balance in the system using experimental data obtained based on the gas flow rates, gas concentrations, and adsorption time when equilibrium was attained. The flow diagram for the experimental set-up is presented in Fig. 1.

\section{Model description}

An existing model which incorporates vapor pressure parameter was adapted from a previous study by Chou and Chiou (1997) and was used to predict the numerical effect of moisture on the adsorption capacity of polyaspartamide. The model was modified to suit the conditions in this study and experimental data were imputed into the model with respective vapor pressure parameters. A new adsorption capacity of polyaspartamide, noting the moisture presence, was then obtained from the model. Details on the assumptions, boundary conditions and full description of the Dubinin-Raduskevich model as used in this study has been reported by the original developers of the model (Chou and Chiou 1997). The adsorption of gases as a single 


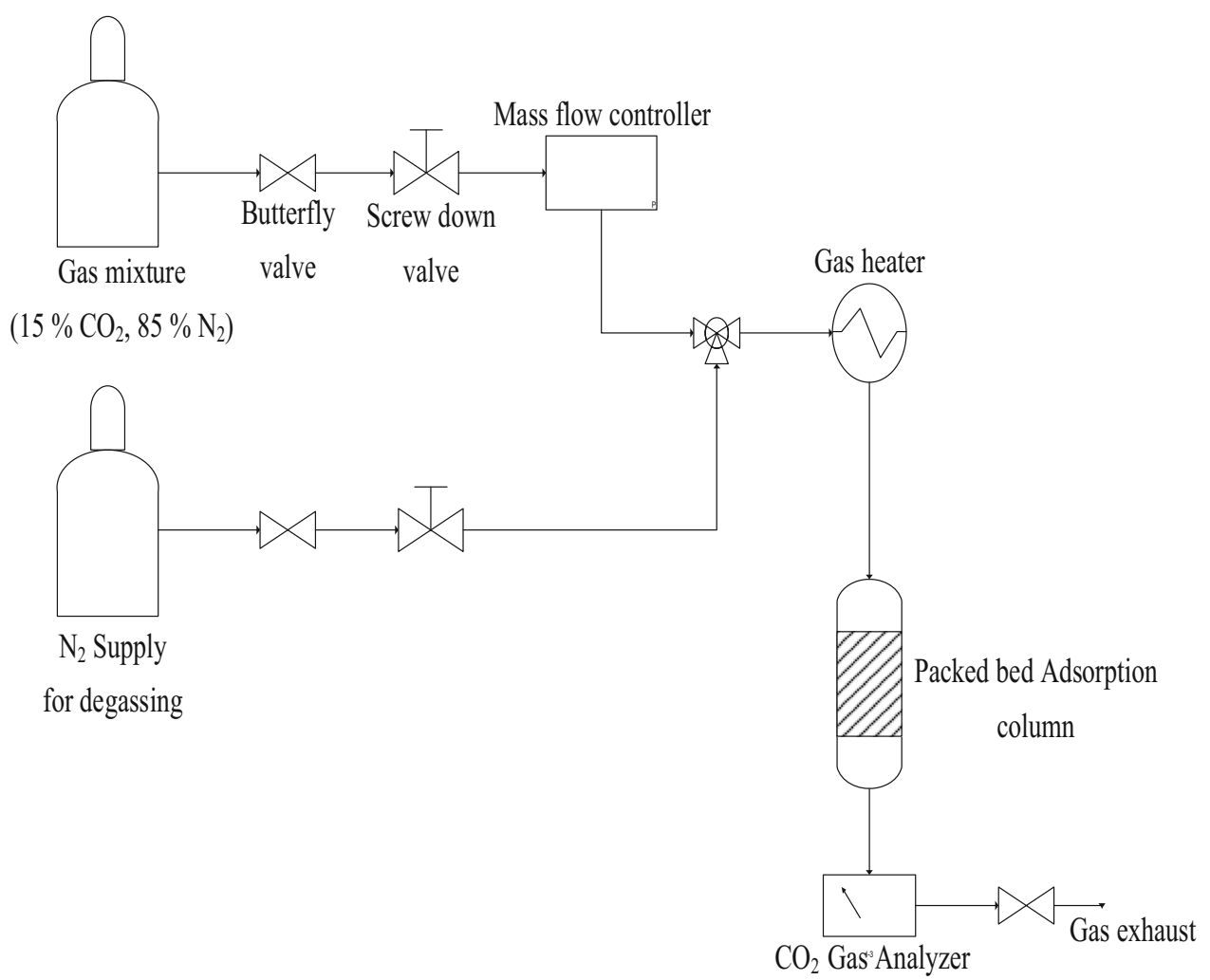

Fig. 1 Flow adsorption setup for the $\mathrm{CO}_{2}$ separation from simulated flue gas. (Adapted from Yoro et al. (2017))

component onto polyaspartamide was then quantified using the Dubinin-Raduskevich equation as shown in Eq. 1:

$q_{a}=\rho_{a} W_{a} \exp \left[-K_{a}\left(\frac{R T \ln P a_{s}}{P_{a}}\right)^{2}\right]$

where $\quad q_{a}$ represents the adsorption capacity; $\rho_{a}$ is the density of $\mathrm{CO}_{2} ; W_{a}$ is the limiting adsorption volume for $\mathrm{CO}_{2} ; \mathrm{Pa}_{s}$ is the saturated vapor pressure of $\mathrm{CO}_{2} ; P_{a}$ is the vapor pressure in the presence of moisture; $\mathrm{T}$ is the temperature in Kelvin; $\mathrm{R}$ is the universal gas constant and $\mathrm{K}_{\mathrm{a}}$, is the molar volume of the gas $\left(\mathrm{CO}_{2}\right)$.

The experimental data obtained were further fitted to standard adsorption isotherms (Langmuir and Freundlich adsorption). The adsorption isotherm models for Langmuir and Freundlich are presented in Eqs. (2) and (3), respectively:

$q=\frac{q_{m K P_{\mathrm{CO}_{2}}}}{1+K P_{\mathrm{CO}_{2}}}$

$q_{e=} K_{f} C_{e}^{1 / n}$

where $q$ is the amount of $\mathrm{CO}_{2}$ adsorbed at the pressure $\mathrm{P}$; $q_{m}$ is the amount of $\mathrm{CO}_{2}$ adsorbed with monolayer coverage; and $K$ is the Langmuir constant. While $q_{e}$ is the equilibrium amount of $\mathrm{CO}_{2}$ adsorbed; $K_{f}$ is the adsorption constant; $C_{e}$ is the equilibrium concentration of $\mathrm{CO}_{2}$ and $\mathrm{n}$ is the adsorption intensity of the Freundlich model.

\section{Results and discussion}

\subsection{Effect of moisture}

Most physical adsorbents for $\mathrm{CO}_{2}$ capture have less tolerance for water vapour in the gas feed (Ünveren et al. 2017; Saiwan et al. 2014); but we envisage that polyaspartamide will exhibit a high tolerance level for moisture unlike other physical adsorbents because of its amine-impregnation and the fact that it can function both as a physical or chemical adsorbent. $\mathrm{CO}_{2}$ uptake by polyaspartamide is expected to increase in the presence of moisture due to the interactions between amine and $\mathrm{CO}_{2}$. A bicarbonate compound is formed when $\mathrm{CO}_{2}$ reacts with a primary amine group in polyaspartamide under wet conditions while carbamate is formed under dry conditions according to the schemes in the chemical Eqs. (4) and (5) presented below (Stowe et al. 2015).

$\mathrm{RNH}_{2}+\mathrm{CO}_{2}+\mathrm{H}_{2} \mathrm{O} \rightleftharpoons \mathrm{RNH}_{3}^{+} \mathrm{HCO}_{3}^{-}$(bicarbonate)

$2\left(\mathrm{RNH}_{2}\right)+\mathrm{CO}_{2} \rightleftharpoons \mathrm{RNHCO}_{2}^{-} \mathrm{RNH}_{3}^{+}($carbamate $)$ 
Bicarbonate is a major specie formed during $\mathrm{CO}_{2}$ capture via an aqueous amine process, such as monoethanolamine (MEA), diethanolamine (DEA), and other hindered amines. The result presented in Fig. 2 shows that the model predicted an adsorption capacity of $365.6 \mathrm{mg} / \mathrm{g}$ instead of $330.1 \mathrm{mg} / \mathrm{g}$ obtained using experimental approach (dry conditions). The result in Fig. 2 shows an increase in the adsorption capacity of polyaspartamide in the presence of moisture. Adsorption capacity is expected to increase to almost double in the presence of moisture. However, only a slight increase was observed in this study because most of the micro pores on the surface of the material have been occupied by $\mathrm{CO}_{2}$ molecules and also saturated. Therefore, there will be no room for a further increase in the adsorption capacity of polyaspartamide. The slight increase in the adsorption capacity of polyaspartamide in this study could also be attributed to the hydration interaction of $\mathrm{CO}_{2}$ and adsorbed water on the surface of the adsorbent as reported by $\mathrm{Li}$ et al. (2009a, b) as well as Baltrusaitis and Grassian (2005). This is in line with previous reports in literature

Findings from this study reveal that although polyaspartamide shows high tolerance for moisture (hydrophilic), its adsorption capacity improves slightly in the presence of moisture due to chemical adsorption of $\mathrm{CO}_{2}$ resulting in bicarbonate formation as well as the pore structure, the surface area, the degree and type of functionalization as well as the amine impregnation of polyaspartamide. This makes polyaspartamide a very suitable material for $\mathrm{CO}_{2}$ capture from flue gas streams. The findings reported in this study agrees with that of a similar study reported for a polyamine-based solid adsorbent which is a similar material to the adsorbent considered in this study (Goeppert et al. 2011). Moisture have also been reported in the past to enhance the adsorption capacity as well as the amine

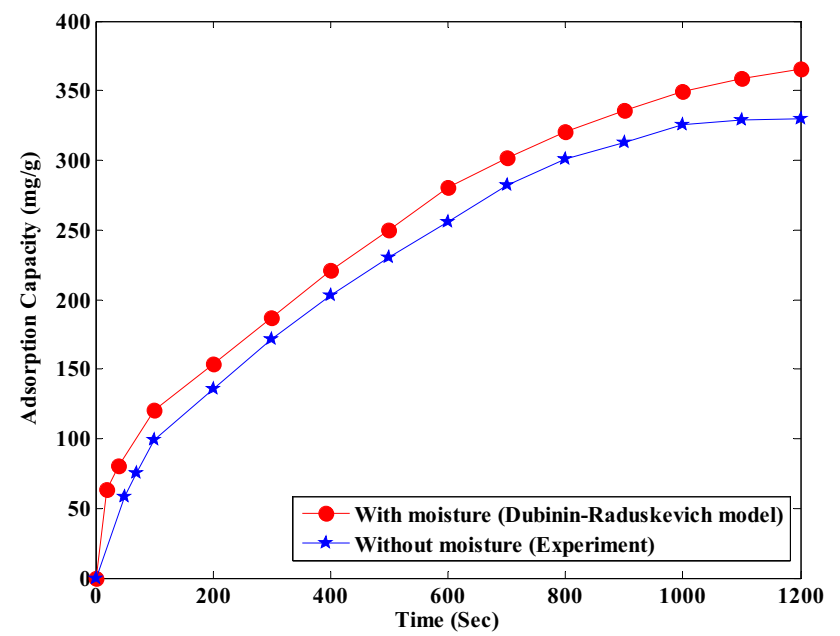

Fig. 2 Theoretical and experimental effect of moisture on the $\mathrm{CO}_{2}$ adsorption capacity of polyaspartamide efficiency of tetraethylenepentamine (TEPA), polyethylenimine (PEI impregnated) ( $\mathrm{Yu}$ and Chuang 2017), and 3-aminopropyltrimethoxysilane (APS) grafted silica sorbents during $\mathrm{CO}_{2}$ capture (Hahn et al. 2015; Stuckert and Yang 2011). In all the aforementioned reports, enhancement effect of moisture on adsorption capacity was also attributed to the formation of bicarbonate which is very similar to the claim in this study.

\subsection{Effect of temperature}

To investigate the effect of temperature on the adsorption capacity of polyaspartamide, data obtained from the experiments conducted at 403,418 and $433 \mathrm{~K}$ were analysed. These temperatures were chosen because Chitsiga et al. (2016) reported that polyaspartamide is usually thermally stable at about $210{ }^{\circ} \mathrm{C}(483 \mathrm{~K})$. Since adsorption is a temperature dependent surface phenomenon favoured by lower temperatures, any further decrease in temperature below $403 \mathrm{~K}$ is expected to result to a higher adsorption capacity before equilibrium is attained and the material gets saturated. In this work, the highest adsorption capacity was observed at $403 \mathrm{~K}$ (the lowest temperature); hence we speculate here that the optimum temperature for this study is the lowest temperature (403 K).

The adsorption isotherms in this study exhibited a monolayer adsorption mechanism for both models. The isotherms also displayed a common behaviour notwithstanding the operating temperature as depicted in Figs. 3 and 4. The results further revealed that Langmuir isotherm shows a superior fit to the adsorption data in this study (see Fig. 3). The increase in the adsorption capacity with decrease in temperature illustrates that $\mathrm{CO}_{2}$ adsorption onto polyaspartamide is an exothermic process. The adsorption isotherms presented in this study generally

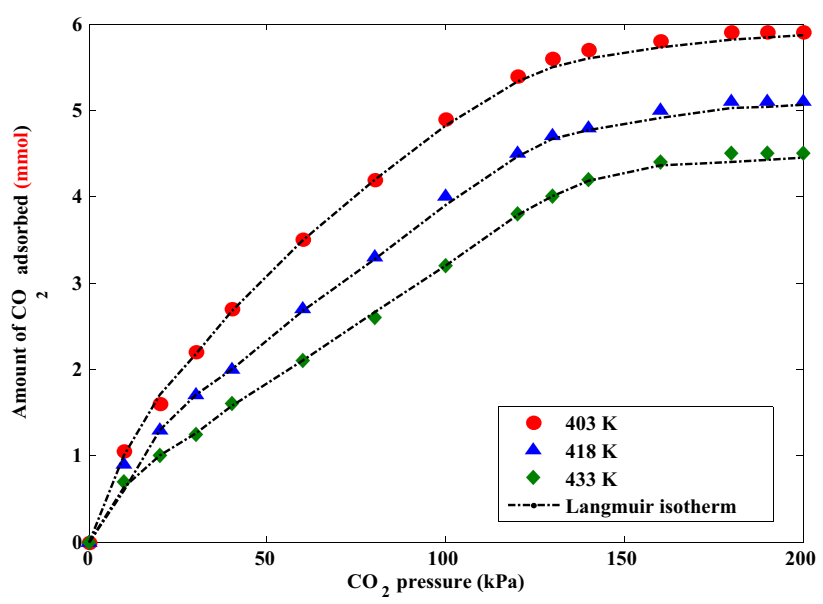

Fig. $3 \mathrm{CO}_{2}$ adsorption isotherms of polyaspartamide at various temperatures (experimental vs Langmuir isotherm) 
described the influence of temperature on the amount of $\mathrm{CO}_{2}$ adsorbed by polyaspartamide. The amount of $\mathrm{CO}_{2}$ capturable by polyaspartamide was $5.9 \mathrm{mmol}$ of $\mathrm{CO}_{2}$ at $403 \mathrm{~K}$ while $4.5 \mathrm{mmol}$ of $\mathrm{CO}_{2}$ was captured by polyaspartamide at $433 \mathrm{~K}$, constant pressure of $200 \mathrm{kPa}$ and gas inlet flow rate of $1.5 \mathrm{~mL} / \mathrm{s}$ as shown in Fig. 3. This implies that the ideal temperature for the adsorption of $\mathrm{CO}_{2}$ by polyaspartamide at a laboratory level as presented in this study is $403 \mathrm{~K}$. Values for the Langmuir isotherm parameters obtained in this study were compared with values recently reported in a similar study by (Khalili et al. 2016) and presented in Table 1; while values for the Freundlich isotherm parameters are presented in Table 2 and Fig. 4. The results obtained confirm that at lower temperatures, the adsorption capacity of polyaspartamide improves steadily just like other adsorbents reported in literature (Alhwaige et al. 2016; Siriwardane et al. 2005; Titinchi et al. 2014; Zhang et al. 2013, 2014c). The observations in this study are in agreement with a recent report by Auta et al. (2013); but an opposite pattern was observed with amines commonly used for $\mathrm{CO}_{2}$ absorption in liquid phase polyethylenimines such as monoethanolamine and diethanolamine reported by Goeppert et al. (2010). The increasing absorption capacity of polyethylenimine-based sorbents with increasing temperature is attributed to the nature of polyethylenimines. With increasing temperature, the viscosity of polyethylenimines diminishes. Diminishing viscosity at higher temperatures improves the reaction kinetics of $\mathrm{CO}_{2}$ with the amino groups of the absorbent, thereby improving the $\mathrm{CO}_{2}$ adsorption. Polyaspartamide can easily be regenerated and desorption of $\mathrm{CO}_{2}$ from polyaspartamide is possible when the temperature is raised slightly above $450 \mathrm{~K}$. However, desorption and regeneration is not discussed in detail in this work because it does not fall within the scope of this report. It will be reported in our future research.

\subsection{Effect of operating pressure}

Pressure is an important parameter in studying the behaviour and adsorption capacity of solid sorbents (Yoro et al. 2017). Mathematically, the amount of $\mathrm{CO}_{2}$ adsorbed by an

Table 1 Constant model parameters for the Langmuir isotherm at different temperatures compared with literature

\begin{tabular}{lllll}
\hline$T(\mathrm{~K})$ & $q_{m}(\mathrm{mg} / \mathrm{g})$ & $K\left(\mathrm{kPa}^{-1}\right)$ & $R^{2}$ & References \\
\hline 288 & 4.131 & 0.026 & 0.984 & Khalili et al. (2016) \\
298 & 3.812 & 0.020 & 0.987 & Khalili et al. (2016) \\
308 & 2.879 & 0.018 & 0.992 & Khalili et al. (2016) \\
288 & 7.420 & 0.017 & 0.991 & This study \\
298 & 6.150 & 0.012 & 0.994 & This study \\
308 & 4.985 & 0.005 & 0.998 & This study \\
\hline
\end{tabular}

Table 2 Constant model parameters for Freundlich isotherm at different temperatures compared with literature

\begin{tabular}{lllll}
\hline$T(\mathrm{~K})$ & $K_{f}(\mathrm{mg} / \mathrm{g})$ & $n$ & $R^{2}$ & References \\
\hline 288 & 1.140 & 1.587 & 0.995 & Khalili et al. (2016) \\
298 & 1.110 & 1.451 & 0.996 & Khalili et al. (2016) \\
308 & 0.992 & 1.434 & 0.996 & Khalili et al. (2016) \\
288 & 1.320 & 1.840 & 0.720 & This study \\
298 & 1.224 & 1.690 & 0.800 & This study \\
308 & 1.150 & 1.520 & 0.892 & This study \\
\hline
\end{tabular}

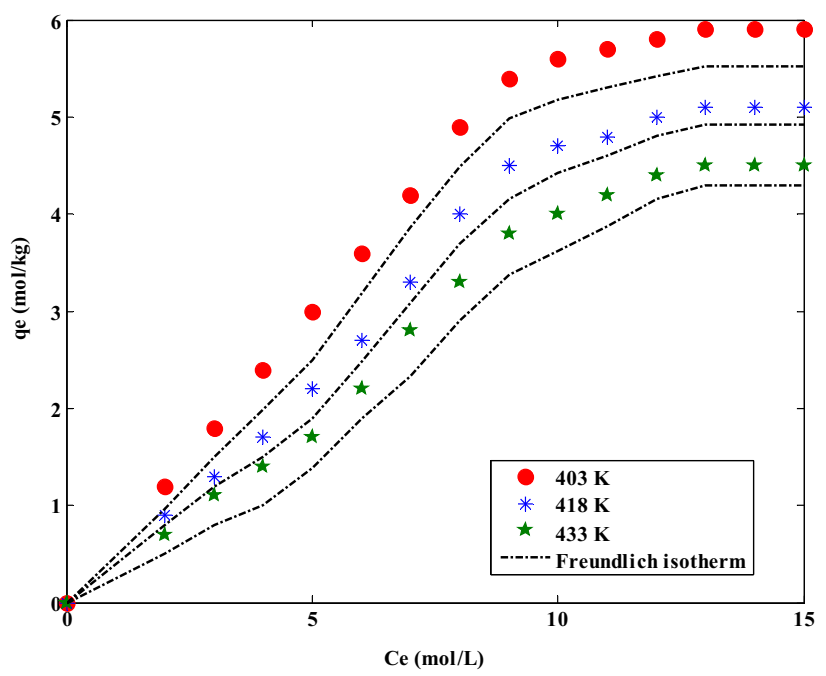

Fig. $4 \mathrm{CO}_{2}$ adsorption isotherms of polyaspartamide at various temperatures (experimental vs Freundlich isotherm)

adsorbent is directly proportional to the operating pressure. According to the results presented in Fig. 5, at higher operating pressure, the $\mathrm{CO}_{2}$ adsorption capacity of polyaspartamide increased and lower operating pressures resulted in a decreased adsorption capacity of polyaspartamide at the same operating temperature. The adsorption capacities of polyaspartamide obtained in this study were 350,330 and $320 \mathrm{mgCO}_{2} / \mathrm{g}$ adsorbent at varying operating pressure of 200,150 and $100 \mathrm{kPa}$, respectively. The adsorption capacities reported in this study were obtained from experiments conducted in a packed bed adsorption column at an operating temperature of $403 \mathrm{~K}$. The maximum adsorption capacity of polyaspartamide reported in this study $\left(350 \mathrm{mgCO}_{2} / \mathrm{g}\right.$ adsorbent) was obtained at the highest pressure of $200 \mathrm{kPa}$ in this study using a gas composition of $15 \% \mathrm{CO}_{2}$ and $85 \% \mathrm{~N}_{2}$. This value is higher than that reported by Chitsiga et al. (2016), where the authors reported an adsorption capacity of $44 \mathrm{mgCO}_{2} / \mathrm{g}$ using a $100 \% \mathrm{CO}_{2}$ source in a thermogravimetric analyzer (TGA) under the same operating conditions. The higher adsorption capacity reported herein could be attributed to 


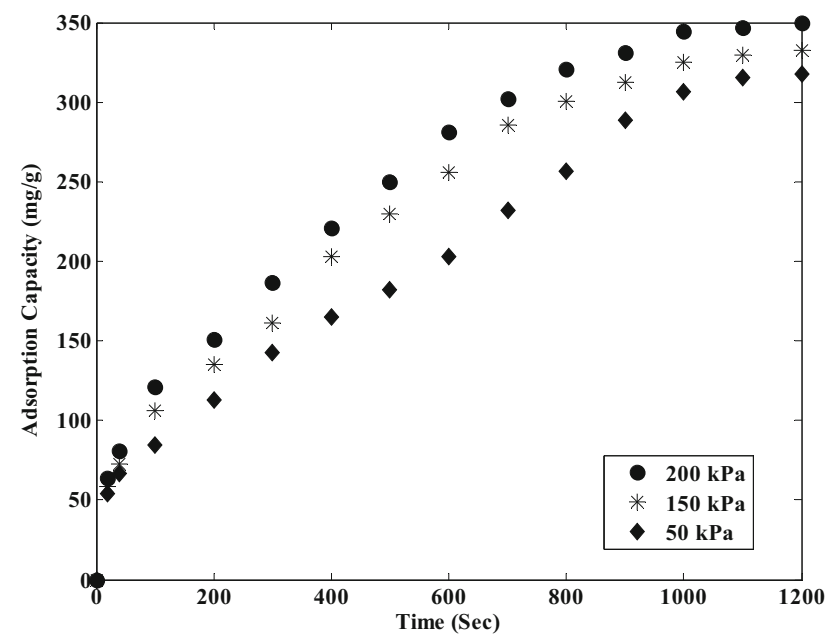

Fig. 5 Effect of operating pressure on the adsorption capacity of polyaspartamide

the closer contact between the adsorbent (Polyaspartamide) and the adsorbate $\left(\mathrm{CO}_{2}\right)$ within the packed bed and increased residence time due to packings in the column than in the thermogravimetric analyzer used by Chitsiga et al. (2016). The different composition of gases used in both studies also contributed to the high adsorption capacity obtained in this study. In summary, findings from this study show that higher operating pressure resulted in an improved adsorption capacity of polyaspartamide.

\subsection{Effect of gas flow rate}

The results for adsorption of $\mathrm{CO}_{2}$ onto polyaspartamide at different gas flowrates is presented in Fig. 6. It was observed that decreasing the inlet gas flow rate increases the contact time and therefore improves the adsorption capacity of polyaspartamide. This implies that, faster flow rates decrease the retention time of $\mathrm{CO}_{2}$ molecules on polyaspartamide within the packed bed system thereby resulting in a reduced adsorption capacity. Longer residence times are required for higher adsorption capacities. Based on the results presented in Fig. 6, the maximum amount of $\mathrm{CO}_{2}$ adsorbed by polyaspartamide at different flow rates of 1.5, 2.0 and $2.5 \mathrm{~mL} / \mathrm{s} \mathrm{CO}_{2}$ were 7.0, 6.0 and $5.8 \mathrm{mg} \mathrm{CO}_{2} / \mathrm{g}$ of adsorbent while the adsorption capacities were 350,330 and $320 \mathrm{mgCO}_{2} / \mathrm{g}$ adsorbent as presented in Fig. 5.

In addition, Fig. 6 shows that as the gas flow rate increases from 1.5 to $2.5 \mathrm{~mL} / \mathrm{s}$, the adsorption curve becomes steeper and the breakpoint time also decreases from 600 to $500 \mathrm{~s}$. This observation is in agreement with the studies reported by Auta et al. (2013) and Tan et al. (2014). Gas flow rates of 90, 120 and $150 \mathrm{~mL} / \mathrm{min}$ were compared against the adsorption capacity of a NaOH-

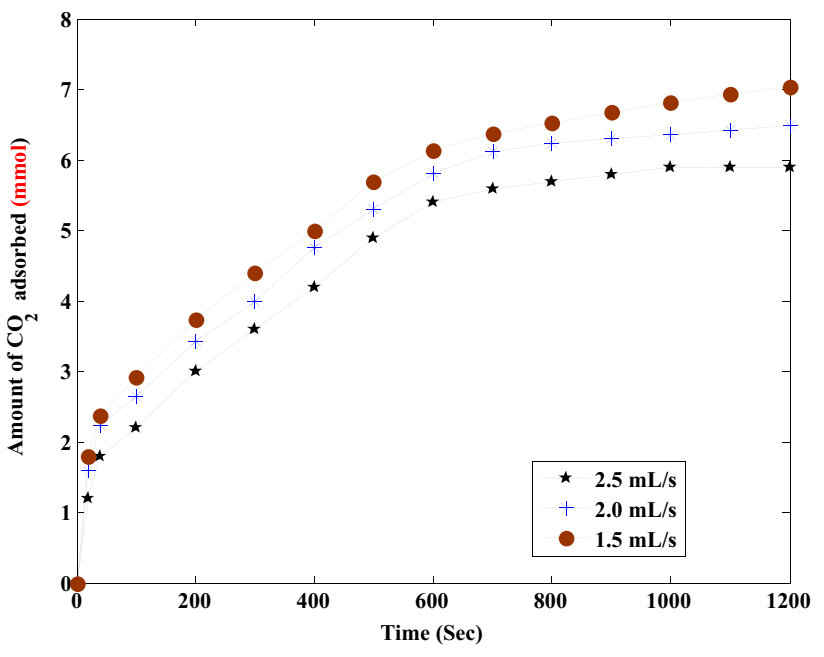

Fig. 6 Effect of gas flow rates on the amount of $\mathrm{CO}_{2}$ adsorbed onto polyaspartamide

modified coconut shell activated carbon (32ACSH3) by Tan et al. (2014). The researchers also reported that the slowest flow rate of $90 \mathrm{~mL} / \mathrm{min}$ produced a longer breakthrough time compared with the highest flow rate of $150 \mathrm{~mL} / \mathrm{min}$. Hence, they concluded that longer dwelling times at lower flow rates allow for slower $\mathrm{CO}_{2}$ diffusion, which leads to a higher adsorption capacity. Auta et al. (2013) also conducted a similar study with the same gas flowrates reported by Tan et al. (2014) using a sodium hydroxide modified activated alumina and the authors also arrived at the same conclusion reported in this study. Information on the effect of gas flow rate provided in this study can be used for mass transfer study as well as designing and operating an industrial-sized adsorption column.

\section{Conclusions and recommendations}

Behaviour of polyaspartamide during $\mathrm{CO}_{2}$ capture was studied under different experimental conditions; including gas flow rate, adsorption temperature, operating pressure in a packed bed adsorption column while the effect of moisture on the adsorption capacity of polyaspartamide was theoretically investigated using a mathematical modelling approach. Results obtained from the packed-bed adsorption experiments reveal that feed flow rate of $1.5 \mathrm{~mL} / \mathrm{s}$ at a constant adsorbent loading of $1.0 \mathrm{~g}$, operating pressure of $200 \mathrm{kPa}$ and adsorption temperature of $403 \mathrm{~K}$ are good for the adsorption of $\mathrm{CO}_{2}$ at a laboratory scale while the Dubinin-Raduskevich model accurately predicted that the presence of moisture has a promoting effect on the adsorption capacity of polyaspartamide. Validation of the model prediction in this study using experimental approach 
would be a very good topic for future research. Other major findings from this study are:

(1) Adsorption of $\mathrm{CO}_{2}$ onto polyaspartamide is controlled by both physisorption and Chemisorption.

(2) Simply targeting high $\mathrm{CO}_{2}$ adsorption capacities alone is quite inadequate to conclude on the potential of an emerging adsorbent like polyaspartamide for effective $\mathrm{CO}_{2}$ capture. But when other criteria such as the influence of operating parameters are included in the specifications for new materials as described in this study, polyaspartamide looks promising as an effective material for $\mathrm{CO}_{2}$ capture.

(3) Further research should be carried out on the desorption, regeneration and application of the adsorbent reported herein towards the removal of $\mathrm{CO}_{2}$ from coal-fired power plants at a pilot or industrial scale.

(4) Economic analysis may also be performed in future research to determine how cost-effective it would be to use polyaspartamide for $\mathrm{CO}_{2}$ capture on a large scale.

Acknowledgements The financial support received from the National Research Foundation of South Africa (NRF-block Grant Number 107867) and University of the Witwatersrand through the Postgraduate Merit Award (WITS-PMA 2018) is highly appreciated.

\section{Compliance with ethical standards}

Conflict of interest There is no conflict of interest regarding the publication of this research article.

Open Access This article is distributed under the terms of the Creative Commons Attribution 4.0 International License (http://crea tivecommons.org/licenses/by/4.0/), which permits unrestricted use, distribution, and reproduction in any medium, provided you give appropriate credit to the original author(s) and the source, provide a link to the Creative Commons license, and indicate if changes were made.

\section{References}

Alhassan M, Andrew I, Auta M, Umaru M, Garba MU, Isah AG, Alhassan B (2017) Comparative studies of $\mathrm{CO}_{2}$ capture using acid and base modified activated carbon from sugarcane bagasse. Biofuels. https://doi.org/10.1080/17597269.2017.1306680

Alhwaige AA, Ishida H, Qutubuddin S (2016) Carbon aerogels with excellent $\mathrm{CO}_{2}$ adsorption capacity synthesized from clay-reinforced biobased chitosan-polybenzoxazine nanocomposites. ACS Sustain Chem Eng 4:1286-1295

Amponsah NY, Troldborg M, Kington B, Aalders I, Hough RL (2014) Greenhouse gas emissions from renewable energy sources: a review of lifecycle considerations. Renew Sustain Energy Rev 39:461-475

Auta M, Amat-Darbis ND, Moh'd-Din AT, Hameed BH (2013) Fixed-bed column adsorption of carbon dioxide by sodium hydroxide modified activated alumina. Chem Eng J 233:80-87
Baltrusaitis J, Grassian VH (2005) Surface reaction of carbon dioxide at the adsorbed water-iron oxide interface. J Phys Chem B 109:12227-12230

Belmabkhout Y, Guillerm V, Eddaoudi M (2016) Low concentration $\mathrm{CO}_{2}$ capture using physical adsorbents: are metal-organic frameworks becoming the new benchmark materials? Chem Eng J 296:386-397

Bezerra DP, Francisco WM, Pedro AS et al (2014) $\mathrm{CO}_{2}$ adsorption in amine-grafted zeolite 13X. Appl Surf Sci 314:314-321

Cheung O, Hedin N (2014) Zeolites and related sorbents with narrow pores for $\mathrm{CO}_{2}$ separation from flue gas. RSC $\mathrm{Adv}$ 4:14480-14494

Chitsiga T, Daramola MO, Wagner N, Ngoy J (2016) Effect of the presence of water-soluble amines on the carbon dioxide $\left(\mathrm{CO}_{2}\right)$ adsorption capacity of amine-grafted poly-succinimide (PSI) adsorbent during $\mathrm{CO}_{2}$ capture. Energy Procedia 86:90-105

Chitsiga TL, Daramola MO, Wagner N, Ngoy J (2018) Parametric effect of adsorption variables on $\mathrm{CO}_{2}$ adsorption of aminegrafted polyaspartamide composite adsorbent during post-combustion $\mathrm{CO}_{2}$ capture: a response surface methodology approach. Int J Oil Gas Coal Technol 17:321-336

Chou MS, Chiou JH (1997) Modeling effects of moisture on adsorption capacity of activated carbon for VOCs. J Environ Eng 123:437-443

Chowdhury S, Parshetti GK, Balasubramanian R (2015) Postcombustion $\mathrm{CO}_{2}$ capture using mesoporous $\mathrm{TiO}_{2} /$ graphene oxide nanocomposites. Chem Eng J 263:374-384

Cuéllar-Franca RM, Azapagic A (2015) Carbon capture, storage and utilisation technologies: a critical analysis and comparison of their life cycle environmental impacts. $\mathrm{J} \mathrm{CO}_{2}$ Util 9:82-102

Ding N, Li H, Feng X, Wang Q, Wang S, Ma L, Zhou J, Wang B (2016) Partitioning MOF-5 into confined and hydrophobic compartments for carbon capture under humid conditions. J Am Chem Soc 138:10100-10103

Donald-Carruthers J, Petruska MA, Sturm EA, Wilson SM (2012) Molecular sieve carbons for $\mathrm{CO}_{2}$ capture. Microporous Mesoporous Mater 154:62-67

Fracaroli AM, Furukawa H, Suzuki M, Dodd M, Okajima S, Gándara F, Reimer JA, Yaghi OM (2014) Metal-organic frameworks with precisely designed interior for carbon dioxide capture in the presence of water. J Am Chem Soc 136:8863-8866

Goeppert A, Meth S, Prakash GKS, Olah GA (2010) Nanostructured silica as a support for regenerable high-capacity organoaminebased $\mathrm{CO}_{2}$ sorbents. Energy Environ Sci 3:1949-1960

Goeppert A, Czaun M, May RB, Prakash GKS, Olah GA, Narayanan SR (2011) Carbon dioxide capture from the air using a polyamine based regenerable solid adsorbent. J Am Chem Soc 133:20164-20167

Guangzhi Y, Jinyu Y, Yuhua Y, Zhihong T, DengGuang Y, Junhe Y (2017) Preparation and $\mathrm{CO}_{2}$ adsorption properties of porous carbon from camphor leaves by hydrothermal carbonization and sequential potassium hydroxide activation. RSC Adv 7:4152-4160

Hahn MW, Steib M, Jentys A, Lercher JA (2015) Mechanism and kinetics of $\mathrm{CO}_{2}$ adsorption on surface bonded amines. J Phys Chem C 119:4126-4135

Hao W, Björnerbäck F, Trushkina Y, Oregui-Bengoechea M, SalazarAlvarez G, Barth T, Hedin N (2017) High-performance magnetic activated carbon from solid waste from Lignin conversion processes. 1. Their use as adsorbents for $\mathrm{CO}_{2}$. ACS Sustain Chem Eng 5:3087-3095

Hefti M, Marx D, Joss L, Mazzotti M (2014) Model-based process design of adsorption processes for $\mathrm{CO}_{2}$ capture in the presence of moisture. Energy Procedia 63:2152-2159

Khalili S, Ghoreyshi AA, Jahanshahi M, Khoshandam B (2016) Predictions of the adsorption equilibrium of $\mathrm{CO}_{2} / \mathrm{O}_{2}$ mixture on 
multi-walled carbon nanotube using ideal adsorbed solution theory. J Water Environ Nanotechnol 1:9-17

Kim HJ, Oba M, Pittella F, Nomoto T, Cabral H, Matsumoto Y, Miyata K, Nishiyama N, Kataoka K (2012) PEG-detachable cationic polyaspartamide derivatives bearing stearoyl moieties for systemic siRNA delivery toward subcutaneous BxPC3 pancreatic tumor. J Drug Target 20:33-42

Lee SY, Park SJ (2015) A review on solid adsorbents for carbon dioxide capture. J Ind Eng Chem 23:1-11

Lee S, Filburn TP, Gray M, Park J, Song H (2008) Screening test of solid amine sorbents for $\mathrm{CO}_{2}$ capture. Ind Eng Chem Res 47:7419-7423

Leung DYC, Caramanna G, Maroto-Valer MM (2014) An overview of current status of carbon dioxide capture and storage technologies. Renew Sustain Energy Rev 39:426-443

Li G, Xiao P, Webley P (2009a) Binary adsorption equilibrium of carbon dioxide and water vapor on activated alumina. Langmuir 25:10666-10675

Li G, Xiao P, Webley PA, Zhang J, Singh R (2009b) Competition of $\mathrm{CO}_{2} / \mathrm{H}_{2} \mathrm{O}$ in adsorption based $\mathrm{CO}_{2}$ capture. Energy Procedia $1: 1123-1130$

Li B, Duan Y, Luebke D, Morreale B (2013) Advances in $\mathrm{CO}_{2}$ capture technology: a patent review. Appl Energy 102:1439-1447

Li K, Jiang J, Tian S, Yan F, Chen X (2015) Polyethyleneimine-nano silica composites: a low-cost and promising adsorbent for $\mathrm{CO}_{2}$ capture. J Mater Chem A 3:2166-2175

Marx D, Joss L, Hefti M, Pini R, Mazzotti M (2013) The role of water in adsorption-based $\mathrm{CO}_{2}$ capture systems. Energy Procedia 37:107-114

Miyata K, Oba M, Nakanishi M, Fukushima S, Yamasaki Y, Koyama H, Nishiyama N, Kataoka K (2008) Polyplexes from poly (aspartamide) bearing 1,2-diaminoethane side chains induce $\mathrm{pH}$ selective, endosomal membrane destabilization with amplified transfection and negligible cytotoxicity. J Am Chem Soc 130:16287-16294

Moon JR, Kim MW, Kim D, Jeong JH, Kim JH (2011) Synthesis and self-assembly behavior of novel polyaspartamide derivatives for anti-tumor drug delivery. Colloid Polym Sci 289:63-71

Ngoy JM, Wagner N, Riboldi L, Bolland O (2014) $\mathrm{A} \mathrm{CO}_{2}$ capture technology using multiwalled carbon nanotubes with polyaspartamide surfactant. Energy Procedia 63:2230-2248

Ngoy JM, Daramola MO, Chitsiga TL, Falcon R, Wagner N (2017) $\mathrm{CO}_{2}$ adsorption using water-soluble polyaspartamide. S Afr J Chem Eng 23:139-144

Ntiamoah A, Ling J, Xiao P, Webley PA, Zhai Y (2016) $\mathrm{CO}_{2}$ capture by temperature swing adsorption: use of hot $\mathrm{CO}_{2}$-rich gas for regeneration. Ind Eng Chem Res 55:703-713

Osler K, Dheda D, Ngoy J, Wagner N, Daramola MO (2017a) Synthesis and evaluation of carbon nanotubes composite adsorbent for $\mathrm{CO}_{2}$ capture: a comparative study of $\mathrm{CO}_{2}$ adsorption capacity of single-walled and multi-walled carbon nanotubes. Int J Coal Sci Tech 4:41-49

Osler K, Twala N, Oluwasina OO, Daramola MO (2017b) Synthesis and performance evaluation of chitosan/carbon nanotube (chitosan/MWCNT) composite adsorbent for post-combustion carbon dioxide capture. Energy Procedia 114:2330-2335

Qi S, Hay KJ, Cal MP (2000) Predicting humidity effect on adsorption capacity of activated carbon for water-immiscible organic vapors. Adv Environ Res 4:357-362

Saiwan C, Muchan P, Montigny D, Tontiwachwutikul P (2014) Carbon dioxide adsorption. II. Effect of amine functionalization. Energy Procedia 63:2317-2322

Samanta A, Zhao A, Shimizu GKH, Sarkar P, Gupta R (2012) Postcombustion $\mathrm{CO}_{2}$ capture using solid sorbents: a review. Ind Eng Chem Res 51:1438-1463
Scapino L, Zondag HA, Van-Bael J, Diriken J, Rindt CCM (2017) Sorption heat storage for long-term low-temperature applications: a review on the advancements at material and prototype scale. Appl Energy 190:920-948

Sekoai PT, Yoro KO (2016) Biofuel development initiatives in subSaharan Africa: opportunities and challenges. Climate 4:33

Sekoai PT, Yoro KO, Daramola MO (2016) Batch fermentative biohydrogen production process using immobilized anaerobic sludge from organic solid waste. Environments 3:38

Sekoai PT, Yoro KO, Bodunrin MO, Ayeni AO, Daramola MO (2018) Integrated system approach to dark fermentative biohydrogen production for enhanced yield, energy efficiency and substrate recovery. Rev Environ Sci Bio/Technol 17:501-529

Singo MC, Molepo XC, Oluwasina OO, Daramola MO (2017) Chitosan-impregnated Sod-Metal Organic Frameworks (SodZMOF) for $\mathrm{CO}_{2}$ Capture: Synthesis and Performance Evaluation. Energy Procedia 114:2429-2440

Siriwardane RV, Shen MS, Fisher EP, Losch J (2005) Adsorption of $\mathrm{CO}_{2}$ on zeolites at moderate temperatures. Energy Fuels 19:1153-1159

Stowe HM, Vilčiauskas L, Paek E, Hwang GS (2015) On the origin of preferred bicarbonate production from carbon dioxide $\left(\mathrm{CO}_{2}\right)$ capture in aqueous 2-amino-2-methyl-1-propanol (AMP). Phys Chem Chem Phys 17:29184-29192

Stuckert NR, Yang RT (2011) $\mathrm{CO}_{2}$ capture from the atmosphere and simultaneous concentration using zeolites and amine-grafted SBA-15. Environ Sci Technol 45:10257-10264

Tan YL, Islam MA, Asif M, Hameed BH (2014) Adsorption of carbon dioxide by sodium hydroxide-modified granular coconut shell activated carbon in a fixed bed. Energy 77:926-931

Titinchi SJJ, Piet M, Abbo HS, Bolland O, Schwieger W (2014) Chemically modified solid adsorbents for $\mathrm{CO}_{2}$ capture. Energy Procedia 63:8153-8160

Ünveren EE, Monkul BO, Sarığlan S, Karademir N, Alper E (2017) Solid amine sorbents for $\mathrm{CO}_{2}$ capture by chemical adsorption: a review. Petroleum 3:37-50

Vargas DP, Giraldo L, Moreno-Piraján JC (2012) $\mathrm{CO}_{2}$ adsorption on activated carbon honeycomb-monoliths: a comparison of Langmuir and Tóth models. Int J Mol Sci 13:8388-8397

Veneman R, Frigka N, Zhao W, Li Z, Kersten S, Brilman W (2015) Adsorption of $\mathrm{H}_{2} \mathrm{O}$ and $\mathrm{CO}_{2}$ on supported amine sorbents. Int $\mathrm{J}$ Greenh Gas Control 41:268-275

Xu X, Song C, Andresen JM, Miller BG, Scaroni AW (2002) Novel polyethylenimine-modified mesoporous molecular sieve of MCM-41 type as high-capacity adsorbent for $\mathrm{CO}_{2}$ capture. Energy Fuels 16:1463-1469

Xu X, Song C, Miller BG, Scaroni AW (2005) Influence of moisture on $\mathrm{CO}_{2}$ separation from gas mixture by a nanoporous adsorbent based on polyethylenimine-modified molecular sieve MCM- 41 . Ind Eng Chem Res 44:8113-8119

Xu D, Zhang J, Li G, Xiao P, Webley P, Zhai Y (2011) Effect of water vapor from power station flue gas on $\mathrm{CO}_{2}$ capture by vacuum swing adsorption with activated carbon. J Fuel Chem Technol 39:169-174

Yoro KO (2017) Numerical simulation of $\mathrm{CO}_{2}$ adsorption behaviour of polyaspartamide adsorbent for post-combustion $\mathrm{CO}_{2}$ capture. M. Sc. thesis. University of the Witwatersrand

Yoro KO, Sekoai PT (2016) The potential of $\mathrm{CO}_{2}$ capture and storage technology in South Africa's coal-fired thermal power plants. Environments 3:24

Yoro KO, Singo M, Daramola MO, Mulopo JL (2016) Mathematical modeling of adsorption behaviour of SOD-ZMOF/chitosan adsorbent during post-combustion $\mathrm{CO}_{2}$ capture. In: Proceedings of the 33rd annual international pittsburgh coal conference. Omnipress, Capetown, South Africa 
Yoro KO, Singo M, Mulopo JL, Daramola MO (2017) Modelling and experimental study of the $\mathrm{CO}_{2}$ adsorption behaviour of polyaspartamide as an adsorbent during post-combustion $\mathrm{CO}_{2}$ capture. Energy Procedia 114:1643-1664

$\mathrm{Yu}$ J, Chuang SSC (2017) The role of water in $\mathrm{CO}_{2}$ capture by amine. Ind Eng Chem Res 56:6337-6347

Yu Q, de la Delgado JP, Veneman R, Brilman DWF (2017) Stability of a benzyl amine based $\mathrm{CO}_{2}$ capture adsorbent in view of regeneration strategies. Ind Eng Chem Res 56:3259-3269

Zhang C, Song W, Sun G, Xie L, Wang J, Li K, Sun C, Liu H, Snape $\mathrm{CE}$, Drage $\mathrm{T}$ (2013) $\mathrm{CO}_{2}$ capture with activated carbon grafted by nitrogenous functional groups. Energy Fuels 27:4818-4823
Zhang W, Liu H, Sun C, Drage TC, Snape CE (2014a) Performance of polyethyleneimine-silica adsorbent for post-combustion $\mathrm{CO}_{2}$ capture in a bubbling fluidized bed. Chem Eng J 251:293-303

Zhang Z, Yao ZZ, Xiang S, Chen B (2014b) Perspective of microporous metal-organic frameworks for $\mathrm{CO}_{2}$ capture and separation. Energy Environ Sci 7:2868-2899

Zhang Z, Wang B, Sun Q (2014c) Fly ash-derived solid amine sorbents for $\mathrm{CO}_{2}$ capture from flue gas. Energy Procedia 63:2367-2373 